
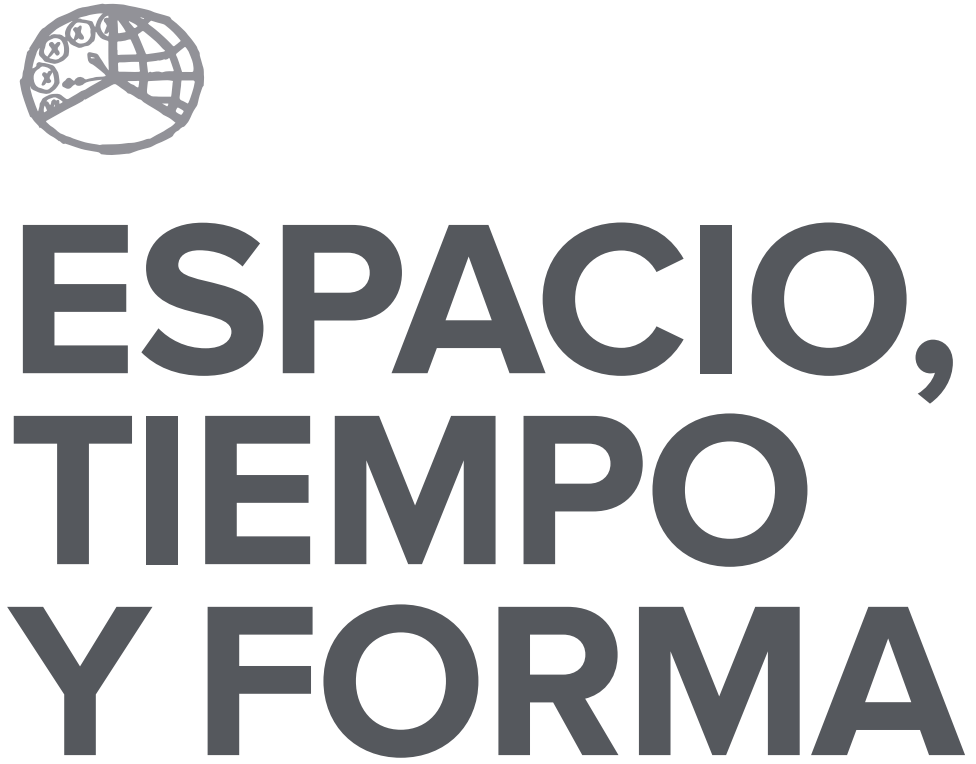

AÑO 2018

ISSN 0214-9745

E-ISSN 2340-1362

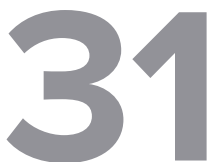

SERIE III HISTORIA MEDIEVAL

REVISTA DE LA FACULTAD DE GEOGRAFÍA E HISTORIA 



\section{ARTÍCULOS · ARTICLES}





\title{
UN RESUMEN DEL TRATADO JURÍDICO DE AL-TAFRI': EL MANUSCRITO ÁRABE 1233 DEL MONASTERIO DE EL ESCORIAL Y SU SUPUESTA RELACIÓN CON LEYES DE MOROS
}

\section{A SUMMARY OF AL-TAFRI'S LEGAL TREATY: THE ARAB MANUSCRIPT 1233 OF THE MONASTERY OF EL ESCORIAL AND ITS SUPPOSED RELATION TO LEYES DE MOROS}

\author{
Soha Abboud Haggar \\ Recepción: 2017/04/19 · Comunicación de observaciones de evaluadores: 2017/09/27 . \\ Aceptación: 2017/11/7 \\ DOI: http://dx.doi.org/10.5944/etfiii.31.2018.21334
}

\section{Resumen}

El manuscrito árabe I233, de la Biblioteca del Real Monasterio de El Escorial y el manuscrito II38 de la Biblioteca de al-Qarawiyyin en Fez contienen una copia completa de al-Sahl al-Badī' fi Ihtișār al-Tafrì -que se traduciría por «El sencillo resumen adornado de al-Tafri'»-, una obra escrita por el alfaquí Ibn Ğamìl, del siglo XIV. El libro es un resumen del tratado jurídico de al-Tafrĭ de Ibn al-Ğallāb, conocido y muy difundido desde al-Andalus omeya hasta el final de la época morisca en el siglo XVII. La hipótesis de trabajo consistía en ver la relación entre este resumen árabe y Leyes de Moros que es también un resumen de al-Tafrit en romance castellano, sobre el que he publicado numerosos estudios.

\section{Palabras clave}

al-Tafrǐ́; Ibn al-Ğallāb, Leyes de Moros; Ibn Ğamīl; Manuscrito I233, Real Monasterio de El Escorial; manuscrito de al-Tafrï ms.232; manuscrito del Corán aljamiado ms.235; Biblioteca Provincial de Toledo. 


\begin{abstract}
The Arabic manuscript 233 from the Library of the Royal Monastery of El Escorial and manuscript II3 8 from the al-Qarawiyyin Library in Fez contain a complete copy of al-Sahl al-Badī fi ikhtișār al-Tafrī -which would be translated as «The simple ornate summary of al-Tafri «, a work written by Ibn Ğamil in the fourteenth century. The book is a summary of the legal treatise of al-Tafrì of Ibn al-Ğallāb, well-known and widespread in al-Andalus from the Umayyad period until the end of the Morisco era in the seventeenth century. The working hypothesis consists in studying the relationship between this Arabic summary and the Leyes de Moros (The laws of the Moors) which is also a summary of al-Tafri in Castilian romance on which I have published numerous studies.
\end{abstract}

\title{
Keywords
}

al-Tafrî́; Ibn al-Ğallāb; Leyes de Moros; Ibn Ğamīl; Arabic Manuscript I233, El Escorial Royal Monastry; Manuscript of al-Tafrī ms.232; Corán aljamiado manuscript ms. 235; Municipal Library of Toledo. 


\section{AL-TAFRI' Y SU RESUMEN EN LENGUA ÁRABE}

Entre los manuscritos árabes conservados en la Biblioteca del Real Monasterio de El Escorial, con la signatura I233, se conserva la preciosa y completa copia de una obra titulada al-Sahl al-Badī fi Ihtisar al-Tafrī -que se traduciría por «El sencillo resumen adornado de $a l-T a f r i{ }^{-} »-$ escrita por un alfaquí conocido por Ibn Ğamīl (m. I3I5). De esta misma obra he localizado y estudiado sobre CD otra copia manuscrita completa de la Biblioteca de al-Qarawiyyin en Fez con la signatura II38.

Después de confirmar que lo que se resumía en este manuscrito en sus dos copias era el tratado jurídico de al-Tafrǐ , escrito por Abu 1-Qāsim 'Ubayd Allāh Ibn al-Ğallāb del siglo $\mathrm{X}^{2}$-cuya traducción aljamiada en una copia del siglo XVI fue objeto de mi tesis doctoral ${ }^{3}$ y sobre la que he seguido trabajando durante años ${ }^{-4}$, me pareció imprescindible estudiar el resumen por esta relación directa con el tratado jurídico.

El resumen de al-Tafrì era obra de Shams al-Din Abu 'Abdallah Muhammad b. Abi al-Qāsim b. 'Abd al-Salām al-Rab'ī, conocido por Ibn Ğamīl' (I24I-I3I5). Tunecino de nacimiento, trabajó en El Cairo y escribió su libro en una fecha indeterminada entre finales del XIII y comienzos del XIV como se puede asumir por la fecha de su muerte. Nada indicaba que la obra hubiera sido editada y tras varios intentos para averiguarlo -con viajes incluidos- me rendí ante la posibilidad de que no lo fuera, debido, con toda probabilidad, a lo que he ido descubriendo: la

2. Abu l-Qāsim 'Ubayd Allāh Ibn al-Ğallāb, nacido en Basora, murió en Bagdad en el año 998d.C. (véase su biografía en Ibn Farḥūn, Burhan al-Din Ibrahim, al-Dibağ al-mudhab fi ma'rifat a'yan 'ulama' al-madhab, ed. M. al-Ahmad Abu I-Nur, El Cairo, 1982, vol. I, 461). Su libro jurídico, al-Tafrî, fue editado por Ḥusayn al-Dahmani, Beirut, 1987. En el año 2007se volvió a publicar, esta vez editado por S. Kisrawi con el título al-Tafrì fi Figh Mälik b. Anas, Dar al-Kutub al-'Ilmiyya, Beirut.

3. Аввoud-HagGAR, Soha, (1999a), El tratado jurídico de al-Tafrïde lbn al-Ğalläb, Zaragoza, 2 volúmenes. La tesis, defendida en la UCM en el año 1997, se puede consultar on-line en la web de la UCM y contiene, aparte del estudio y el glosario, la fotocopia del original del manuscrito.

4. Aвboud-HAGGAR, Soha, «al-Ğihād, según el manuscrito aljamiado de al-Tafrī de Ibn al- Ğalläb», Sharq alAndalus 12 (1995), 325-338; (1997b), «Leyes musulmanas y fiscalidad mudéjar», Actas del VI Congreso Internacional de Estudios Medievales, León, 169-205; (1999b), «Difusión del tratado jurídico de al-Tafrī de Ibn al- Ğallāb en el Occidente musulmán», en Aragón en la Edad Media. Homenaje a Carmen Orcástegui, Universidad de Zaragoza, Zaragoza, vol. II, 1-18; (2000a), «EI calco semántico. Un procedimiento de traducción al romance entre mudéjares y moriscos», Cuestiones de actualidad en lengua española, ed. BORREGo NIETO et alii, Salamanca, 141-148; (2000b), «Puntualización sobre el manuscrito J-XXXIII y otros manuscritos aljamiados», Alqantara, 237-240; (2001), «De extranjerismos a arabismos. Ejemplos extraídos de una traducción al romance bajomedieval», en Nuevas aportaciones al estudio de la Lengua Española», ed. J.A. BARTOL et alii, Salamanca, 75-82; (2003a), «El tratado jurídico islámico de al-Tafrī en el manuscrito morisco T232 de la B.P. de Toledo, en caracteres latinos, fechado en 1607》, en Grafeyón. Libros, códices y manuscritos. Estudios históricos y sicológicos, Córdoba, 241-257; (2006), «Entre manuscrito aljamiado y original árabe. Al-Tafri' de Ibn al-Ğallāb y al-Ḥișnu al-ḥașinn de Ibn alĞazari», en Los manuscritos árabes en España y Marruecos, coord. M.J. VIGUera Molins y C. CASTILLO, Granada, 209-231; (2008a), «Los manuscritos de al-Tafrî̀ de Ibn al- Ğalläb en España», en Hacia un itinerario del manuscrito andalusí, ed. M. Ammadi, Madrid, 43-56; (2010) «Los manuscritos de al-Tafrī en Marruecos y España: formas y contenidos», en Itinerario del manuscrito andalusí sufí, Universidad de Casablanca, Marruecos, 153-162; (2012a), «El tratado jurídico de Al-Tafrí , un vínculo entre Iraq y al-Andalus», Manuscritos para comunicar culturas. Quinta primavera del manuscrito andalusí, editado por F. VIDAL y M. AmmADI, Casablanca, 11-26; (2012b), «La literatura de los Moriscos», Los moriscos. Una mirada de cuatro siglos después de su expulsión, coordinado por Fernando Díaz Esteban, editorial Actas, Madrid, 2012, 54-69; (2012c), «La literatura aljamiada traducida del árabe», Aljamías. In memoriam. Álvaro Galmés de Fuentes y lacob Hassán, editado por R. SUÁREZ García e Ignacio Ceballos, Biblioteca Arabo-románica et islámica, Ediciones Trea, Gijón, 13-43.

5. KahHALA, 1960, Mu 'ğam al-mu'allifîn. Tarāğim mușannifî al-kutub al-'arabiyya, Damasco, vol. 11, 141. 
poca calidad del resumen. De hecho, llevé a cabo unas amplias catas comparándole con el original árabe de al-Tafrī y comprobé que, aunque seguía todos los libros jurídicos del tratado con sus epígrafes, el texto resumido era, en su mayor parte, inconexo y poco comprensible.

\section{AL-TAFRI' Y SU RESUMEN EN ROMANCE: LAS LEYES DE MOROS}

Evidentemente, este resumen me interesó todavía más porque había estudiado largamente el famosísimo libro Leyes de Moros editado por Pascual de Gayangos en el año i853 en dos amplios trabajos:

En el primero, publicado en el año I997 con el título «Las Leyes de Moros son el libro de al-Tafrī» concluía que este libro era una copia parcial, fragmentaria, resumida y con interpolaciones del tratado de Ibn al-Ğallāb.

El segundo trabajo consistió en revisar el libro Leyes de Moros desde su original manuscrito. Debo aclarar que el original que revisé no fue la copia manuscrita que le sirvió a Gayangos como original en el siglo XIX sino su auténtico original manuscrito que se remonta al siglo XV y que se daba por perdido. Efectivamente, antes de que el tratado de Leyes de Moros viese la luz en Madrid en I853, su manuscrito original había pasado por tres etapas:

La primera, fue la copia manuscrita del siglo XV, conservada desde el año I95I en la Universidad de Uppsala en Suecia como parte de la colección del hispanista sueco Günnar Tilander y catalogada actualmente como «Manuscrito español I» de su legado. El filólogo sueco había dado noticias de este manuscrito en el año I967 en un artículo sobre las fuentes jurídicas como elemento constitutivo de la lengua española, en el que escribió: «En I95I, tuve la buena fortuna de tropezar con el códice [de Leyes de Moros], que pude adquirir para mi propia biblioteca. Hace falta una nueva edición de las Leyes de Moros [respecto de la de Gayangos] basada en el manuscrito del siglo XIV que he sacado a luz. El futuro editor de las leyes de los mudéjares debe conocer bien la lengua árabe, pues son numerosísimos los arabismos esparcidos en el texto». ${ }^{6}$

La segunda etapa de Leyes de Moros consistió en las dos copias manuscritas que se hicieron del referido original de Uppsala en I794. Una de ellas se conserva en la Biblioteca de la Real Academia de la Historia con la signatura II/9396 y la otra está en la Biblioteca Nacional de Madrid con la signatura Ms. 44I5. El título conocido,

6. Tilander, G., «Fuentes jurídicas», en Enciclopedia Lingüística Hispánica. Tomo II. Elementos constitutivos. Fuentes, Madrid, 1967, 447-60. Estas palabras de Tilander me animaron a dedicar un estudio a estos arabismos que publiqué en 2003 (AвBOUD-HAGGAR, S., (2003C), «Los arabismos de 'Leyes de moros', revisados desde su manuscrito original recuperado», Hommage à l'Ecole d'Oviedo d'Etudes aljamiado, dédié au fondateur Álvaro Galmés de Fuentes, edición de A. Temimi, Zaghouan, 33-46). 
Leyes de Moros, aparece en estas dos copias de I794 y no en el manuscrito de Uppsala. En la de la RAH (Ms.II/9396) el manuscrito lo encabeza la leyenda «Copia del manuscrito complutense, cuyo título es Leyes de Moros» y la de la BNM se titula en la primera guarda Leyes de Moros y al comienzo del tratado «Copia del manuscrito complutense, cuyo título es Leyes de Moros» como el primero. Ambas sirvieron de base única para la edición que hizo Gayangos en el siglo XIX y en la que lamentó muchas veces la desaparición del original; así, entre otras muchas apreciaciones, Gayangos dejó escrito en la introducción «El códice original se ha extraviado, siendo tanto más de sentir su pérdida...».7

La tercera etapa fue la edición de I853 hecha por Gayangos, gracias a la cual se dio a conocer el texto que cobró el relieve que lo acompañó durante decenas de años. ${ }^{8}$

Así que, sobre el verdadero original de Leyes de Moros conservado manuscrito en la biblioteca de la Universidad de Uppsala y cuya fotocopia había conseguido gracias a la gestión del profesor Galmés de Fuentes, realicé personal e íntegramente la nueva edición que revisé con el profesor Galmés antes de su fallecimiento en febrero de 2002.9

Examinado, editado y estudiado el «Manuscrito Español I» de la Universidad de Uppsala llegué a las siguientes conclusiones:

I. Su realización se remonta a la primera mitad del siglo XV, como muestra el examen paleográfico de la escritura gótica libraria o textual con algunos rasgos de cursividad. ${ }^{\text {Io }}$ Añádase a esto una inscripción de un bibliotecario en el segundo folio de guarda que indica que es un manuscrito de mediados del siglo XV. Estas observaciones sitúan claramente el Leyes de Moros en la época mudéjar.

7. Gayangos, 1853,3 .

8. Abboud-Haggar, 1997. La historia del manuscrito se detalla en la ficha de catalogación de la copia 11/9396 de la RAH elaborada por el profesor Galmés de Fuentes (Los manuscritos aljamiado-moriscos de la Biblioteca de la Real Academia de la Historia. Legado Pascual de Gayangos, Madrid, 1998).

9. Sigo a la espera de publicar esta edición y su estudio, probablemente en la Editorial Trea de Oviedo.

10. Según el resultado del examen paleográfica de la escritura gótica libraria o textual con algunos rasgos de cursividad del manuscrito que efectuó la Dra. Paloma Cuenca Muñoz, profesora titular de Paleografía la Universidad Complutense, a la que agradezco su criterio experto en el estudio paleográfico de la fotocopia del manuscrito, se llegan a las siguientes conclusiones: 1. el grado de evolución de la «s» en sus variantes morfológicas de «s» de doble curva que aparece con valor de «z» e, incluso con forma sigmática que demuestran un grado de evolución propia de este momento (fol. 19r, I. 22; fol 15v, I. 23 y 24: cosa y pasa); 2. la letra «d» aparece en sus variantes de recta y uncial, y dentro de esta última forma ha comenzado a desarrollar el ojo que ya en algunos casos le sirve para unir con la letra siguiente (fol. 19r, I. 14: después); 3 . las anotaciones marginales, realizadas en el mismo tipo de escritura, pero con un ductus mucho más cursivo que el resto del texto, muestra un grado de evolución de la escritura gótica propio ya del siglo XV como lo demuestran las «q» que envuelven; 4. el sistema abreviativo es el propio del siglo XV; 5 . en lo que se refiere a nexos y ligados, encontramos algunos nexos del momento precisado como el «cr» (fol. 24r, l. 13: criador), «ci» (fol. 24r, l. 13) y «do» (fol. 24r, l.13 criador). Queda descartada por tanto, las suposiciones varias sobre la fecha del original, como la que hizo el propio Tilander que lo remontó al siglo XIV (véase Tilander, 1967, pg. 457) o incluso al siglo XIII como lo hizo P. Sánchez Camacho, copista del siglo XVIII en su copia conservada en BNM (manuscrito Ms. 4415). 
2. Procede del ámbito del Reino de Castilla: los mismos arabismos muestran un desarrollo propio del ámbito castellano y no del aragonés, como ya Gayangos había observado en la introducción a su estudio. ${ }^{\text {II }}$

3. Según he comprobado personalmente y como ya se sabía por la edición de Gayangos, el manuscrito sólo contiene la segunda mitad del tratado de al-Tafri $i$, con lo cual no es de extrañar que sea acéfalo, sin título ni nombre de autor, aunque le fuera añadido un título más tarde, tal vez en el XVIIl, Leyes de los Moros de España. La copia no lleva fecha y es de copista desconocido.

4. Probablemente, esta copia mudéjar sea, a su vez, copia de una anterior en vista de las diversas confusiones cometidas en numerosos préstamos del árabe, suponiendo que el que hiciera esta copia no dominara la terminología árabe que generó estos préstamos, muchos de los cuales fueron convertidos en conocidos arabismos. ${ }^{12}$

\section{NUEVA HIPÓTESIS DE TRABAJO}

La pregunta que se planteaba entonces era: si el Leyes de Moros es un resumen de al-Tafrī y el manuscrito árabe de El Escorial de Ibn Ğamīl también lo es, ¿puede el Leyes de Moros ser una traducción de este resumen árabe? Buscar la respuesta a esta hipótesis de trabajo fue la siguiente etapa de mi investigación.

Dos hechos eran claros: primero, que al-Tafrī era un tratado jurídico conocido y prestigiado y, por ello, fue utilizado hasta el siglo XVII, copiado numerosas veces y resumido en romance y, segundo, que la práctica de la traducción era extendida entre los mudéjares de al-Andalus; se habían traducido por anónimos el Corán, el al-Tafrì y otros tratados más. ${ }^{13}$

11. Aparte de las características paleográficas del manuscrito de la Universidad de Uppsala, los arabismos muestran un desarrollo propio del ámbito castellano y no del aragonés (Abboud-Haggar, 2003c). Gayangos mismo ya había hecho notar esta pertenencia en su introducción a su edición de «Leyes de moros» $(1853,5)$ así como otros especialistas como Wiegers $(1994,57)$.

12. AbBOUd HagGar, $2003 \mathrm{C}$.

13. Cito a modo indicativo el tratado de al-Tulaytuli (Cervera Fras, M.J., La plegaria musulmana en el Compendio de al-Tulaytuli. Transcripción del manuscrito de Sabiñan (Zaragoza), Zaragoza, 1987; y al-Hișn al-ḥașin de Ibn al-Ğazarī (AвBOUd-HAGGAR, (2004/2005), «lbn al-Ğazarī, el recitador del Corán, un nexo entre Oriente y al-Andalus», Crónicas Azahar, 3 y 4, 25-29, y (2005), «'Uddatu al-Hișni al-ḥașin de Ibn al-Ğazarī al-dimašqī, una muestra de la transmisión de los asuntos religiosos islámicos de Oriente a Occidente», en Anaquel de Estudios Ârabes, 16, 5- 63. Sobre las traducciones del Corán en el ámbito hispánico, véanse ARIAS TORRES, Juan Pablo, (2007), «Bibliografía sobre las traducciones del Alcorán en el ámbito hispánico», Trans. Revista de traductología, 11, 261-272 y LóPEZ-MorILLAS, Consuelo, El Corán de Toledo, Gijón, 2011, pg. 31-81. 


\section{EL PRESTIGIO DE AL-TAFRĪ‘ EN AL-ANDALUS}

El tratado jurídico malikí de al-Tafrī, escrito en Bagdad en el siglo X, había llegado al Occidente islámico a manos de conocidos alfaquíes. ${ }^{\mathrm{I4}}$ En al-Andalus ganó fama y prestigio como uno de los libros malikíes más ortodoxos. Prueba de este prestigio entre los malikíes andalusíes, primero, después entre los mudéjares y, luego, entre los moriscos es la gran cantidad de copias manuscritas que de él se conservan en diversos países islámicos y en España.

Así, de al-Tafrī‘ se conservan copias manuscritas íntegras en Marruecos, en la Biblioteca de al-Qarawiyyin en Fez, donde existen los siguientes manuscritos: uno del año I230 (es la copia más antigua que se conoce de Tafri ${ }^{`}$ hasta ahora); otro copiado en I3Io y otro copiado en una fecha anterior a I493. ${ }^{\text {I5 }}$

En Rabat, existen dos copias en la Biblioteca de Palacio y otras tres copias en la Biblioteca Nacional ${ }^{16}$. En Túnez existe una copia de al-Tafrî en la biblioteca privada de shayj Muhammad al-Shadhli al-Nayfar ${ }^{17}$ y otras dos en la Biblioteca Nacional $^{18}$. Aparte de esto, existe una copia en Argelia, una en Damasco ${ }^{19}$, y otras parciales en Egipto y en Arabia Saudí. En la Biblioteca del Museo Británico en Londres existe una copia íntegra de al-Tafrí‘ con la signatura ADD 952I, que he consultado en un CD; el texto tiene una clara relación epigráfica con el Magreb. ${ }^{20}$

En España también se conservan varias copias completas del original árabe de al-Tafrí ${ }^{`}$. El Codex II73 en la biblioteca de El Escorial, fechado en el año I4I6, en letra magrebí, probablemente importada por Felipe II. ${ }^{2 \mathrm{I}}$ El manuscrito 5I5I de la Biblioteca Nacional de Madrid, sin fecha, escrito con un trazo característico de la mano morisca; esta copia completa del tratado en su lengua original contiene glosas en romance aljamiado en caracteres árabes que muestran que fue copiado y utilizado por algún morisco, lo que significa que el tratado jurídico, en su versión original, interesaba todavía en época morisca a pesar de la pérdida de la lengua. ${ }^{22}$ También en la BNM, el manuscrito 5003 de la Biblioteca Nacional de Madrid,

14. El tratado de al-Tafrī había gozado de gran prestigio en Oriente. Fue en el momento en el que la escuela malikí vivía un período de auge bajo el patrocinio de los califas abasíes quienes habían nombrado entonces cadíes a una serie de ulemas de esta escuela durante los siglos IX y X (Abboud-Haggar, Soha, 1999b y 2012a).

15. Sobre las copias árabes de Tafrī'-muchas de las cuales he examinado en persona- véanse Abboud-Haggar, 2008a, 2008c, 2010.

16. He conseguido ojear y obtener la fotocopia del manuscrito Qaf-466; existen también los manuscritos 27Gim y el 2418 , fechados con nombre de copista, aún sin consultar.

17. Consulta hecha personalmente en una visita a esta biblioteca privada en el año 2010

18. En Túnez se conservan tres copias más que no he podido consultar.

19. No puedo dar noticias de esta copia porque, contrariamente a lo publicado por al-Dahmani en su introducción a su edición de al-Tafrï , no estaba localizada en la Biblioteca Nacional de Damasco en el año 2010.

20. Abboud-Haggar, (2012a).

21. Abboud-Haggar, (2008c), «Bibliotecas moriscas», en Anaquel de Estudios Árabes (Anejo I. serie de monografías): «Actas: Jornadas sobre manuscritos árabes», editado por N. Martínez de Castilla et alii, Madrid, 99-104.

22. Las glosas han sido añadidas al texto en lengua árabe para aclarar detalles relativos a la limosna ritual. 
copiado en $1675 .{ }^{23}$ Finalmente, se conserva una copia en la localidad toledana de Villarubia de Santiago, dada a conocer recientemente y fechada en el año I4I2. ${ }^{24}$

\section{LA PRÁCTICA DE LA TRADUCCIÓN EN AL-ANDALUS: LAS TRADUCCIONES DE AL-TAFRI'}

Por la difusión de al-Tafrī en al-Andalus, y al cabo de un período imposible de calcular después de establecida la condición de mudéjares a los andalusíes que se quedaron en sus tierras, el tratado fue traducido al romance aragonés por algún traductor anónimo luego copiado varias veces por moriscos.

Existen tres copias completas de la traducción al romance aljamiado hechas en época morisca tardía, todas con rasgos aragoneses: el manuscrito J-XXXIII de la Junta (CSIC), en caracteres árabes, objeto de mi tesis doctoral; el manuscrito 4870 de la Biblioteca Nacional de Madrid, en caracteres árabes sin fecha, y el manuscrito ms.232 de la Biblioteca Provincial de Toledo (actualmente, Biblioteca de Castilla-La Mancha en Toledo), finalizado en agosto del año I607 y escrito en caracteres latinos. ${ }^{25}$

El estudio comparativo de estas tres traducciones con el original árabe muestra que todas son totalmente fieles al contenido del original salvo en el emplazamiento de algún capítulo dentro del libro. Muestra también que la copia más antigua, la J-XXXIII fechada en el año I585, se caracteriza por la abundancia en los calcos léxicos y morfo-sintácticos como se ha podido detectar precisamente por la comparativa con el original árabe. En cuanto al estilo de las otras dos traducciones, pues es relativamente sencillo dada la ausencia de estos calcos y la abundancia de los préstamos del árabe. ${ }^{26}$

Del mismo modo, la comparación entre la traducción contenida en el manuscrito 4870 de la BNM, en romance aljamiado en caracteres árabes sin fechar, y la contenida en el manuscrito ms.232 de Toledo, en caracteres latinos fechada en 1607 , muestra que son traducciones idénticas con indicios muy claros de que la de Toledo fue copiada de la de la BNM puesto que el copista incorpora en el texto del ms.232 notas laterales y correcciones hechas en los márgenes de la copia aljamiada en caracteres árabes ${ }^{27}$.

23. Véanse AbBoud-HagGAR, 2008a, 2008c y $2012 a$

24. Pude examinar personalmente esta copia en Villarubia de Santiago. Esta localidad forma parte de la cuenca del Tajo, junto a poblaciones como Ocaña -donde se han encontrado multitud de manuscritos- y el Maestragzo de Uclés, que formaron parte de la Orden de Santiago (véase ArIAS TORRES, en prensa en Aljamía vol. 20-21 [2012]; y Abboud-Haggar, 2012a).

25. Sobre este manuscrito ms.232 o (T 232), identificado con Toledo por ser su primer lugar de conservación, véase AвBOUD-HAGgAR, 2003a. Volveré a hablar de este manuscrito más adelante.

26. Véase el estudio lingüístico y el glosario bilingüe publicados en el primer tomo del libro El tratado jurídico de alTafrī' de Ibn al-Ğalläb, (AвBOUD-HAGGAR, 1999a, vol. I, 43-121 y 127-367, respectivamente), así como Abboud-Haggar, 2001.

27. Así por ejemplo, en el fo.213v, el copista incorpora al texto del ms.232 la siguiente explicación existente en 


\section{AL-TAFRĪ' DE TOLEDO Y EL CORÁN DE TOLEDO}

En este contexto de las traducciones de al-Tafri ${ }^{-}$-y a expensas de una posterior publicación más detallada- me permito incluir en este artículo el resultado de mi última investigación que prueba la relación directa entre el manuscrito ms.232 de al-Tafrí de Toledo y la traducción del Corán conservada en la misma biblioteca y contenida en el manuscrito ms.235 que la profesora López-Morillas publicó con el título de El Corán de Toledo. ${ }^{28}$

a. El examen físico de los dos manuscritos en su lugar de conservación muestra que el papel es de hilo satinado, como se describe en la ficha bibliográfica de al-Tafri` en el catálogo de la Biblioteca Pública de Toledo publicado en I942. ${ }^{29}$ En ambos se utiliza el mismo tipo de tinta como se puede ver del examen ocular.

b. El examen paleográfico de los dos manuscritos muestra claramente que el copista de los dos manuscritos era la misma persona: en ambos manuscritos, numerosas letras tienen un trazo especial: la letra /z/ se eleva sobre la línea, redondeada; el palo de la letra/y/ es excesivamente inclinado hacia la izquierda; la letra /p/ cierra su palo inferior con una raya horizontal; letra /g/ se caracteriza por una parte bajo la línea bastante redondeada y ancha, y la letra /ç/ lleva la cedilla bastante separada de la letra misma. Distingue perfectamente entre la letra /v/ -encima de la letra y de gran tamaño- y la letra / $\mathrm{u} / \mathrm{y}$ la cópula de coordinación /y/ aparece, a veces, envuelta en un trazo largo, salido de la cola de la misma..$^{30}$

\footnotetext{
los márgenes del ms.4870, que dice «y no passa vendida de priestamo [quiere dezir prestame un cahiz de trigo y mercarte otro], y la causa...». Precisamente, por esta relación directa de contenido entre la copia en caracteres árabes (BNM 4870) y la copia en caracteres latinos (Toledo, ms.232) además de la precisión en la estructura de ambas copias, invita a suponer que ambas fueron obra del mismo copista del que se hablará nuevamente más adelante; véase también Abboud-Haggar, 2003a, 244, nota 11. El manuscrito ms.232 ha sido objeto de una tesis doctoral en la Universidad de Manouba (Túnez); la tesis es inédita y no la pude consultar.

28. LóPEZ-MorilLAS, El Corán de Toledo, editorial Trea, 2011; el mismo manuscrito fue editado por Roqué Figuls en el año 2001 (Alcorán, editado por Roqué Figuls con introducción de J. Vernet Ginés, Reial Acadèmia de Bones Lletres y la UNED, Barcelona, 2001).

29. El tipo de papel no se recoge en la ficha de catalogación del manuscrito ms.235 del Corán aunque el examen físico del manuscrito demuestra que es el mismo tipo de papel satinado que el usado en el manuscrito de $a l$-Tafri ${ }^{-c}$ (véase Esteve BARBA, Francisco, Catálogo de la colección de manuscritos Borbón-Lorenzana. Biblioteca Pública de Toledo, editado por el Cuerpo Facultativo de Archiveros, Bibliotecarios y Arqueólogos, Madrid, 1942, pg. 183 (al-Tafrï ) y 185 (el Corán). Creo significativo recalcar que D. Francisco Esteve Barba, el catalogador y estudioso de esta colección de manuscritos, recogió en su catálogo que ambos manuscritos procedían de la Biblioteca Nacional de Madrid donde se habían conservado con dos signaturas correlativas, la 19473 del manuscrito del Corán y la 19474, de al-Tafrī́ .

30. El catalogador, Esteve Barba, escribió en su estudio introductorio: «Los volúmenes árabes de la colección [Lorenzana y Borbón] estaban estudiados por González Palencia en una Miscelánea de estudios y textos árabes, publicado en 1915 por el Centro de Estudios Históricos. Tan sólo uno se añade a dicha publicación: el Alcorán aljamiado (ms. 235), escrito por la misma mano que trazó el Alquiteb de la Tafria, a su juicio tan interesante» (ibídem, pg. 3). Esta anotación final viene en apoyo a lo sugerido en varios de mis estudios anteriores como resultado del examen paleográfico comparativo del manuscrito de al-Tafrï con muestras del manuscrito del Corán e intuido por la profesora López-Morillas (LóPEZ-MoRILLAS, 2011, 26-27).
} 
c. La meticulosa precisión y claridad de la letra y la organización en la elaboración de los índices de los dos manuscritos que realiza el copista en los primeros folios de sus manuscritos es otro de los argumentos a favor de la identificación de los dos copistas como la misma persona. ${ }^{31}$

d. La coincidencia de las fechas de copia viene en apoyo a la identificación del copista de los dos manuscritos como la misma persona: el manuscrito del Corán lleva cuatro fechas indicativas de la finalización de cada una de las partes: 2 de mayo de I606; 3I de mayo de I606, 5 de junio de I6o6 y II de julio de i606. ${ }^{32}$ El manuscrito de al-Tafrī', en cambio, se terminó de copiar en agosto de i607. La concatenación de las fechas de copia es muy plausible en la actividad de un copista.

Como consecuencia de lo argumentado en este apartado, se puede confirmar sin lugar a dudas que el copista del al-Tafri es el mismo copista del manuscrito del Corán de Toledo. Éste, además, había escrito la noticia del nacimiento de su hijo y las circunstancias de su bautizo al comienzo del tratado jurídico, como se verá más abajo, por lo cual se puede suponer que el copista era también el dueño de las dos copias.

\section{PARTIDA DE NACIMIENTO DEL HIJO DEL DUEÑO Y COPISTA DE AL-TAFR $\bar{I}^{\circ}$}

En el primer folio de las guardas anteriores del manuscrito de al-Tafrì, cuya copia había finalizado en agosto de 1607 , el copista escribió con una letra más descuidada que el contenido del libro, lo siguiente:

«Naçióme un fijo, las loores son ad Allah, miercoles al 4 de mayo de 1608 entre las ocho y las nuebe oras de la mañana en la planeta de almuxtari que es Jupiter que es Jobe y la luna en el açauro (préstamo del árabe al-Åawr) que es el toro ... hizo sele fadas a 21 del dicho mes y año. pusele por nombre yahye. bautiçolo nicolas ximeno vecino de Villafeliche a 25 del dicho mismo mes y año. y era el primero de pasqua de mayo. Puso le por nonbre Juan miguel. fue su padrino miguel el marido de beatriz la comadre. naçio el dia de la conjuçion de la luna».33

Cierra el texto el nombre del recién nacido Yahyà Ibn Muhamad Ibn Ibrāhīm banī al-'Azīz, escrito en lengua árabe. ${ }^{34}$ Fue su padre, Muhamad Ibn Ibrāhīm banī

31. Estos índices así como las particularidades paleográficas resaltadas en el renglón anterior se pueden comprobar gracias a la digitalización de ambos manuscritos, dispuestos para la consulta en la web de la Biblioteca Provincial de Toledo online en la siguiente URL:<http://bvpb.mcu.es/es/consulta/busqueda.cmd>. Agradezco a las bibliotecarias de la Biblioteca Provincial de Toledo su opinión experta y su amabilidad.

32. LóPEZ-MORILLAS, 2011, 21-23.

33. (Sic) Todo el extracto está copiado según se encuentra en el manuscrito.

34. Yaḥyà Ibn Muḥamad Ibn Ibrāhīm banī al-'Azīz es el nombre completo del recién nacido, nombre compuesto según la tradición árabe y musulmana en el cual consta el nombre del padre, del abuelo y la pertenencia familiar o tribal, con lo cual se puede suponer que el padre se llamaba Muḥamad Ibn Ibrāhīm banī al-'Azīz. 
al-'Azīz, el copista y dueño de al-Tafrì, quien dejó constancia de la fecha del nacimiento de su hijo y de las dos ceremonias que siguieron al nacimiento: la primera de carácter cristiano y la otra de carácter islámico, las fadas, que describió detalladamente en dos folios en las guardas posteriores al tratado.35

\section{EL COPISTA Y DUEÑO DE LAS DOS COPIAS: EL ALFAQUII DE VILLAFELICHE}

En consecuencia, podemos concluir que Muḥamad Ibn Ibrāhīm banī al-'Azīz, copista y dueño de al-Tafrî , fuera también el copista y dueño de la traducción del Corán. A ambas obras traducidas al aljamiado en un momento indeterminado probablemente por mudéjares- y copiadas en caracteres latinos en el siglo XVII, se les puede aplicar lo que el copista dejó escrito en su copia del Corán, justificando el uso de los caracteres latinos: por el desconocimiento de los moriscos del árabe y por la urgencia que tenía para devolver el libro del que copiaba a quienes se lo habían prestado. ${ }^{36}$

Es relevante destacar que las dos traducciones no estaban en manos de cualquiera. Muḥamad Ibn Ibrāhīm banī al-'Azīz era con toda seguridad versado en la comprensión de estas dos obras fundamentales para un creyente musulmán y actuaría como alfaquí encargado de su aljama de Villafeliche como lo demuestran algunos elementos característicos de la copia del tratado de al-Tafri : las glosas y las notas marginales aclaratorias muestran un uso práctico de la copia y de frecuente consulta por un conocedor de estos libros, naturalmente un alfaquí. Estas notas estaban escritas con frecuencia en caracteres árabes y relativas a temas fundamentales en la vida de una aljama como la cuantía de la limosna, la llamada a la plegaria diaria, entre otros temas; además, la precisión de la estructura interna del contenido jurídico, dividido en libros, capítulos y párrafos, todos bien enumerados, y dos índices, uno al comienzo y otro más detallado al final confirman el uso práctico del libro.37

35. Esta nota del copista de la traducción de al-Tafrì de Toledo y su descripción de la ceremonia de las fadas lo relacionó directamente a él y a los moriscos con otro libro del acervo cultural musulmán que, con toda seguridad, utilizaban los moriscos. Se trata del libro de plegaria de Ibn al-Ğazarī, al-Hișnu al-Hașin, sobre el que hice una serie de estudios de gran interés (véanse ABBOUD-HAGGAR, (2003b), «lbn al-Ğazarī en la literatura aljamiado-morisca a través de los manuscritos J-LII y T-232», Anaquel de Estudios Árabes 14, 21-29; - (2004/2005), «lbn al-Ğazarī, el recitador del Corán, un nexo entre Oriente y al-Andalus», Crónicas Azahar, 3 y 4, 25-29; y (2005), «'Uddatu al-Ḥișni al-ḥașīn de Ibn al-Ğazarī al-dimašqī, una muestra de la transmisión de los asuntos religiosos islámicos de Oriente a Occidente», en Anaquel de Estudios Árabes, 16, 5- 63; (2006), «Entre manuscrito aljamiado y original árabe. al-Tafrî de Ibn al-Ğallāb y al-Hiș̣n al-ḥașin de Ibn al-Ğazarì», en Los manuscritos árabes en España y Marruecos, coord. M.J. VIGUERA Molins y C. CASTILLO, Granada, 209-231.

36. LÓPEZ-MORILLAS, 2011, 21-25.

37. C. López-Morillas sugiere que «el copista del Corán T-235 y del manuscrito T-232 pudo ser el morisco Muhammad Rubio de Villafeliche, a quien encontramos en el exilio en Túnez dos o tres décadas después» (1999-2000, 264 y 2011, 26-27). Estoy intentando editar esta copia de al-Tafrĩ y estudiar sus características lingüísticas y su significado sociológico entre los últimos moriscos. 
La relación probada entre los manuscritos de Toledo, el ms.232 y el ms.235, añade un detalle más a nuestros conocimientos sobre la vida religiosa de los moriscos: las traducciones al romance aljamiado del Corán y del tratado jurídico de al-Tafrī‘ fueron utilizados hasta comienzos del siglo XVII.

\section{A MODO DE CONCLUSIÓN}

El copista y dueño del manuscrito de al-Tafrî de Toledo, identificado como Muhạamad Ibn Ibrāhīm banī al-'Azīz, era también el copista y dueño del Corán; los utilizaba en la lengua que le era más fácil, el romance en letra latina. ${ }^{38}$

La trayectoria del tratado jurídico malikí al-Tafrī desde su llegada a al-Andalus, sus copias en árabe, su traducción al aljamiado en caracteres árabes y latinos es el reflejo de la vida de los musulmanes en al-Andalus y muestra el tratamiento que dispensaban los descendientes de éstos a su legado islámico hasta el siglo XVII.

Así, el morisco tenía una copia del original árabe del tratado jurídico escrita por él. Tenía también una traducción completa al romance aljamiado que se copiaba varias veces y en diferentes formatos y caracteres dependiendo de las necesidades que se tuvieran. Tenía también en aljamiado un resumen hecho por un mudéjar anónimo del siglo XV, que lo resumió como bien pudo en Castilla y que conocemos como las Leyes de Moros. Este resumen no mantiene relación ninguna con el resumen en lengua árabe de Ibn Ğamīl al-Sahl al-Badī fi Ihtịsār al-Tafrì , puesto que, finalizadas las catas entre ellos, se concluye que ambos resúmenes sólo son resúmenes de un mismo original. El manuscrito árabe no es el original del Leyes de Moros que bien pudo haber sido en vista de la actividad de copia y de traducción que giraban alrededor de al-Tafrì.

38. Este romance de los siglos XVI-XVII repleto de préstamos y de calcos del legado islámico se debería describir como la «variedad lingüística aljamiada», escrita tanto en grafía árabe como latina. 


\section{BIBLIOGRAFÍA}

AвbOUD-HAGGAR, S., (I995), «al-Ğihād, según el manuscrito aljamiado de al-Tafrī‘ de Ibn al-Ğallāb», Sharq al-Andalus I2 (I995), 325- 338.

Aвboud-Haggar, S., (i997a), «Las Leyes de Moros son el libro de al-Tafrī», Cuadernos de Historia del Derecho, 4, I63-20I.

AввоUd-Haggar, S., (I997b), «Leyes musulmanas y fiscalidad mudéjar», Actas del VI Congreso Internacional de Estudios Medievales, León, I69-205.

Аввоud-Haggar, S., (I999a), El tratado jurídico de al-Tafrī'de Ibn al-Ğallāb, Zaragoza, 2 volúmenes.

Abboud-Haggar, S., (I999b), «Difusión del tratado jurídico de al-Tafrī de Ibn al-Ğallāb en el Occidente musulmán», en Aragón en la Edad Media. Homenaje a Carmen Orcástegui, Universidad de Zaragoza, Zaragoza, vol. II, I-I8

Aвboud-Haggar, S., (I999c), «Conflicto de jurisdicción en un pleito entre mudéjares. Ágreda I50I», en Cuadernos de Historia del Derecho, 6, 4I5-432.

Aвboud-Haggar, S., (200oa), «El calco semántico. Un procedimiento de traducción al romance entre mudéjares y moriscos», Cuestiones de actualidad en lengua española, ed. Borrego Nieto et alii, Salamanca, I4I-I48.

AвbOUD-Haggar, S., (20oob), «Puntualización sobre el manuscrito J-XXXIII y otros manuscritos aljamiados», Alqantara, 237-240.

AbBoud-HagGar, S., (200I), «De extranjerismos a arabismos. Ejemplos extraídos de una traducción al romance bajomedieval», en Nuevas aportaciones al estudio de la Lengua Española», ed. J.A. Bartol et alii, Salamanca, 75-82.

Aвboud-Haggar, S., (2003a), «El tratado jurídico islámico de al-Tafrī en el manuscrito morisco T232 de la B.P. de Toledo, en caracteres latinos, fechado en I607», en Grafeyón. Libros, códices y manuscritos. Estudios históricos y sicológicos, Córdoba, 24I-257.

AввоUD-HaGgAR, S., (2003b), «Ibn al-Ğazarī en la literatura aljamiado-morisca a través de los manuscritos J-LIl y T-232», Anaquel de Estudios Árabes I4, 2I-29.

Aвboud-Haggar, S., (2003c), «Los arabismos de 'Leyes de Moros', revisados desde su manuscrito original recuperado», Hommage à l'Ecole d'Oviedo d'Etudes aljamiado (dédié au fondateur Álvaro Galmés de Fuentes, edición de A. Temimi, Zaghouan, 33-46.

AввоUd-HagGaR, S., (2004/2005), «Ibn al-Ğazarī, el recitador del Corán, un nexo entre Oriente y al-Andalus», Crónicas Azahar, 3 y 4, 25-29.

Аввоud-Haggar, S., (2005), «'Uddatu al-Ḥiṣni al-Ḥașinn de Ibn al-Ğazarī aldimašqī, una muestra de la transmisión de los asuntos religiosos islámicos de Oriente a Occidente», en Anaquel de Estudios Árabes, 16, 5- 63.

AввоUd-Haggar, S., (2006), «Entre manuscrito aljamiado y original árabe. AlTafrī‘ de Ibn al-Ğallāb y al-Ḥiṣnu al-Ḥașin de Ibn al-Ğazarī», en Los manuscritos árabes en España y Marruecos, coord. M.J. Viguera Molins y C. Castillo, Granada, 209-23I. 
AввоUd-HaGgaR, S., (2008a), «Los manuscritos de al-Tafrī de Ibn al-Ğallāb en España», en Hacia un itinerario del manuscrito andalusí, ed. M. Ammadi, Madrid, 43-56.

Аввоud-Haggar, S., (2008b), «Precedentes andalusíes en la fiscalidad de las comunidades mudéjares», en En la España Medieval, 31, 475-512.

Aвboud-Haggar, S., (2008c), «Bibliotecas moriscas», en Anaquel de Estudios Árabes (Anejo l. serie de monografías): «Actas: Jornadas sobre manuscritos árabes», editado por N. Martínez de Castilla et alii, Madrid, 2008, 99-I04.

Aвboud-Haggar, S., (20I0) «Los manuscritos de al-Tafrĭ en Marruecos y España: formas y contenidos», en Itinerario del manuscrito andalusí sufí, Universidad de Casablanca, Marruecos, I53-I62.

AввоUd-HagGaR, S., (20I2a), «El tratado jurídico de Al-Tafri , un vínculo entre Iraq y al-Andalus», Manuscritos para comunicar culturas. Quinta primavera del manuscrito andalusí, editado por F. Vidal y M. Ammadi, Casablanca, II-26.

Аввоud-Haggar, S., (20I2b), «La literatura de los Moriscos», Los moriscos. Una mirada de cuatro siglos después de su expulsión, coordinado por Fernando Díaz Esteban, editorial Actas, Madrid, 2012, 54-69.

Aвboud-Haggar, S., (2012c), «La literatura aljamiada traducida del árabe», Aljamías. In memoriam. Álvaro Galmés de Fuentes y lacob Hassán, editado por R. Suárez García e Ignacio Ceballos, Biblioteca Arabo-románica et islámica, Ediciones Trea, Gijón, I3-43. Estos artículos se pueden consultar en la siguiente página web de la autora: <www.sohaabboud.com>.

ALCORÁN, (200I), editado por Roqué Figuls con introducción de J. Vernet Ginés, Reial Acadèmia de Bones Lletres y la Universidad Nacional de Educación a Distancia, Barcelona.

Arias Torres, Juan Pablo, (2007), «Bibliografía sobre las traducciones del Alcorán en el ámbito hispánico», en Trans. Revista de traductología, II, 26I-272.

Arias Torres, Juan Pablo, «Una nueva copia del Kitab al-Tafri: el manuscrito árabe de Villarrubia de Santiago (Toledo)», Aljamía, 20-2I (2008-2009), en prensa [2012].

Galmés de Fuentes, Álvaro, (I999), Romania Arabica Iy II. Estudios de literatura comparada árabe y romance, Real Academia de la Historia, Madrid.

Galmés de Fuentes, Álvaro, (I998), Los manuscritos aljamiado-moriscos de la Biblioteca de la Real Academia de la Historia. Legado Pascual de Gayangos, Madrid.

Gayangos, Pascual de, (1985), Leyes de Moros, edición y estudio, Academia de la Historia, Madrid.

IBN FARHÛN, Ibrâhîm, I996, al-Dibāğ al-mudhhab fî ma'rifat a'yân 'ulamâ' almadhhab, edición M. Al-Yannān. Beirut.

IBN AL-ĞALLĀB, Abu al-Qāsim Ubayd Allah, (I987), al-Tafrì , ed. M. Al-Dahmani, Beirut.

IBN ĞAmīl, Shamsu 1-din Abu Abdallah Muḥammad Abdul Salām al-Rab`ī, al-Sahl al-Badī fi Ihtișār al-Tafrī , en dos manuscritos conservados Ms. I233 en El Escorial y Ms. II38 en al-Qarawiyyin (Fez). 
IBN AL-ĞAZARī, Muḥammad, (I955), Kitāb al-Hișni al-Hașīn min kalām Sayyid al-Mursalīn. 'Ala hāmish «Hazinnat al-Asrâr», El Cairo.

IBN AL-ĞAZARĪ, Muhammad, (I995), Uddatu al-Hisnni al-Haṣin min kalām Sayyid al-mursalīn, edición y estudio H. M. Mahlūf, segunda edición, El Cairo.

IBN AL-ĞAZARī, Muḥammad, (I933), Ghāyatu l-nihāya fî tabaqāt al-qurrā', edición y estudio G. Bergstraesser, El Cairo.

KaHнÂla, U.R., (I960), Mu'ğam al-mu'allifîn. Tarāğim musannifî al-kutub al'arabiyya, Damasco.

López-Morillas, Consuelo, (1982), The Qur'an in Sixteenth Century Spain: Six moriscos versions of sura 79, Thames Books, Londres.

López-Morillas, Consuelo, (I983), «Trilingual marginal notes (Arabic, Aljamiado and Spanish) in a Morisco manuscript from Toledo», Journal of Arabic and Oriental Studies, I03-3, 495-504.

López-Morillas, Consuelo, (I995), «Language and identity in late Spanish islam», en Hispanic Review, vol. 63, I93-210.

López-Morillas, Consuelo, (I999-2000), «El Corán romanceado: la traducción contenida en el manuscrito T-235», en Sharq al-Andalus, I6-I7, 263-284.

López-Morillas, Consuelo, (20II), El Corán de Toledo, edición y estudio del manuscrito 235 de la Biblioteca de Castilla-La Mancha, Ediciones Trea, Gijón.

Tilander, G., «Fuentes jurídicas», en Enciclopedia Lingüística Hispánica. Tomo II. Elementos constitutivos. Fuentes, Madrid, I967, 447-60.

Wiegers, G.A., (I994): «Datation et localisation des codices espagnols écrits en caractères arabes (aljamiado): problèmes et perspectives ", en Le manuscrit arabe et la codicologie, ed. A. Ch. Binebine, Rabat, Facultad de Lettres, 2I-30.

Al- ZırıKlî, H., I997, al-A'lām. Qāmūs al-tarāăim, Líbano. 

Calidad de Revistas

científicas Españolas

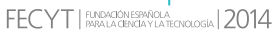

SERIE III HISTORIA MEDIEVAL

REVISTA DE LA FACULTAD DE GEOGRAFÍA E HISTORIA
AÑO 2018

ISSN: 0214-9745

E-ISSN 2340-1362



GREGoRIO DEL SER QUIJANO

Carmelo Luis López, In Memoriam

\section{Artículos · Articles}

29 SOHA ABBOUd Haggar

Un resumen del tratado jurídico de Al-Tafrí: el Manuscrito Árabe 1233 del Monasterio de El Escorial y su supuesta relación con Leyes de Moros

EDUARDo Aznar VALLejo

Norma y conflicto en la navegación castellana bajomedieval

69 Carlos Barquero Goñ

Transferencias de recursos de la Orden de San Juan desde España hasta el Mediterráneo Oriental durante la Edad Media

\section{Margarita Cabrera Sánchez}

La muerte del príncipe Don Juan. Exequias y duelo en Córdoba y Sevilla durante el otoño de 1497

\section{Francisco de Paula Cañas Gálvez}

Primogenitura, continuidad dinástica y legitimitad instituciona en Castilla a principios del siglo XV: Catalina de Trastámara, Princesa de Asturias (1422-†1424)

\section{Paloma Cuenca Muñoz}

El códice visigótico de los Moralia in lob, ms. lat. 83 de la John Rylands Library de Manchester



\section{JOSÉ MARÍA DIAGO JIMÉNEZ}

Las instituciones educativas de carácter religioso en el reino hispanovisigodo de los siglos VI y VII a través de los cánones conciliares y las reglas monásticas

MARÍA Díez Yáñez

La Ética aristotélica en Castilla: las bibliotecas universitarias medievales y prerrenacentistas

\section{Estefanía Ferrer del Río}

Rodrigo de Mendoza, I Marqués del Cenete y I Conde del Cid: paralelismos entre su biografía y su pretendida genealogía

\section{ALEJANDRo García Morilla \\ Escritura publicitaria de transición: entre la visigótica y la carolina.} El paradigma burgalés

María Dolores García Oliva

Señores contra campesinos: un conflicto por la tierra en Mirabel a finales de la Edad Media y principios de los Tiempos Modernos (1488-c. 1520)
34.3 jaime García Carpintero lópez de Mota

La hospitalidad santiaguista a finales de la Edad Media: el proyecto de reconstrucción del hospital de Alarcón

377 LAURA DA GRACIA

La posesión agraria individual en los registros notariales de Fuente el Sol (1481-1482

4.03 Mauricio Herrero Jiménez

El valor de los documentos reales en los procesos de la Real Chancillería de Valladolid

431 Miguel José López-Guadalupe Pallarés

Procesos de señorialización en los concejos de la Extremadura castellano-leonesa. Un estado de la cuestión

455 Ángel Martínez Catalán

Las rentas decimales del cabildo catedralicio de Cuenca a inicios del siglo XV (1400-1432)

4.83 Gonzalo Oliva Manso

Cien años de moneda en Castilla (1172-1268). El siglo del maravedí de oro

521 jesús Olivet García-Dorado

El cabildo de curas y beneficiados de Toledo en la segunda mitad del siglo XV. Composición y aspectos institucionales (1455-1488)

547 Mariel PÉrez

Clérigos rurales, comunidades y formación de las estructuras parroquiales en la diócesis de León (siglos XI-XIII)

575 Milagros Plaza Pedroche

La Orden de Calatrava en la Baja Edad Media (1350-1500): repaso historiográfico

597 Pedro Andrés Porras Arboledas

La pervivencia del Fuero de Cuenca en los inicios de la Modernidad: el testimonio de los fueros de Consuegra y Requena

619 Juan Pablo Rubio Sadia

Los mozárabes frente al rito romano: balance historiográfico de una relación polémica

SANDRA SUÁREZ GARCíA

Los habices de la Vega de Granada como forma de conocimiento del reino nazarí y su transformación tras la conquista: la alquería de La Zubia 


\section{1}

\section{ESPACIO,}

\section{TIEMPO}

\section{Y FORMA}

SERIE III HISTORIA MEDIEVAL

REVISTA DE LA FACULTAD DE GEOGRAFÍA E HISTORIA

\section{De medievalistas ilustres · On Renowned Medievalists}

671 Francisco Abad Nebot

Entradas para un Diccionario

\section{Libros $\cdot$ Books}

679 Almagro Vidal, Clara, Paisajes medievales en el Campo de Calatrava (CARLos BARQUero GoÑI)

681 Carvajal Castro, Álvaro, Bajo la máscara del Regnum. La monarquía asturleonesa en León (854-1037) (JOSÉ MANUEL RODRÍGUEZ GARCíA)

683 Fuente Pérez, María Jesús, Violante de Aragón, reina de Castilla (ANA ECHEVARRía ARsuaga)

687 Martín Prieto, Pablo, Historia del pensamiento medieval: filosofia y teología (FRANCISCO LEÓN FLORIDO)

689 Pardo de Guevara y Valdés, Eduardo (ed.), Mujeres con poder en la Galiciamedieval (siglos XIII-XV). Estudios, biografías y documentos (ENRIQUE CANTERA MONTENEGRO)

693 Ríos Saloma, Martín (ed.), El mundo de los conquistadores (Jessica Ramírez MéndeZ)

690 Solórzano Telechea, Jesús, Arízaga Bolumburu, Beatriz y BOCHACA, Michel (eds.), Las sociedades portuarias de la Europa atlántica en la Edad Media (ANTONIO ORTEGA VILLOSLADA)

703 VAL VALDIVIEso, María Isabel del (coord.), El agua en el
imaginario medieval. Los reinos ibéricos en la Baja Edad Media (MARÍA Jesús Fuente)

707 Villar García, Luis Miguel, Archivo Municipal de Segovia. Documentación medieval, 1166-1474 (ENRIQUE CANTERA MONTENEGRO) 